\title{
The Journal of Space Weather and Space Climate - the first six years: status and evaluation of published papers and policies
}

\author{
Jean Lilensten $^{1, *}$, Anna Belehaki ${ }^{2}$, Jürgen Watermann ${ }^{3}$, Jan Janssens ${ }^{4}$, and Agnès Henri ${ }^{5}$ \\ 1 Editor-in-Chief, Institut de Planétologie et d' Astrophysique de Grenoble, UGA/CNRS-INSU, 38041 Grenoble, France \\ *Corresponding author: jean.lilensten@univ-grenoble-alpes.fr \\ 2 Editor-in-Chief, Institute of Astronomy, Astrophysics, Space Applications and Remote Sensing, National Observatory \\ of Athens, Metaxa and Vas. Pavlou, 15236 Palaia Penteli, Greece \\ 3 Editorial Advisor, jfwConsult, 83400 Tourrettes, France \\ 4 Editorial Secretary, Solar-Terrestrial Centre of Excellence (STCE), Ringlaan-3-Av. Circulaire, 1180 Brussels, Belgium \\ 5 Publishing Director, EDP Sciences, 17 avenue du Hoggar, BP 112, 91944 Les Ulis Cedex A, France
}

\section{Introduction}

The Journal of Space Weather and Space Climate (indexed either as JSWSC or as SWSC) was created at the end of 2010 to fill a gap in the existing peer-reviewed journals (Lilensten \& Belehaki 2011). It is a Gold Open Access journal that publishes papers on all aspects of space weather and space climate from a broad range of scientific and technical fields including solar physics, space plasma physics, aeronomy, planetology, radio science, geophysics, biology, medicine, astronautics, aeronautics, electrical engineering, meteorology, climatology, mathematics, economy, and informatics. The journal was created via a community decision; this has led to its success. This community, representing 24 countries, initially formed the network that established the COST Action ES0803 (Belehaki et al. 2014) and now more experts are joining from all over the world. SWSC publishes only an electronic version where different formats (HTML, PDF, ePUB) are offered. Published articles are freely available online (http://www.swsc-journal.org/) as soon as the editorial work has been completed following acceptance.

Its Editorial Board currently consists of 23 Associate Editors who cover most aspects of the discipline. These Editors have the challenging task of finding reviewers, following the review process and making recommendations to the Editorsin-Chief. The Journal of Space Weather and Space Climate also benefits from an Editorial Secretary and an Editorial Advisor. It is published by EDP Sciences (http://www. edpsciences.org/) and benefits from strong support from the Solar-Terrestrial Centre of Excellence (STCE) in Brussels, Belgium (http://www.stce.be).

\section{Quality standards and impact}

The wider space weather and space climate community, including researchers, engineers, and forecasters, submit regularly articles to SWSC. SWSC is also used as a research tool as it is evident from the number of downloads and citations. The first Impact Factor was published by ThomsonReuters in June 2014, less than four years after its start. The journal's first Impact Factor was 2.519, and has since increased to 2.558 in June 2015 and 2.846 in June 2016. SWSC is indexed in the categories Astronomy and Astrophysics where its rank (in 2015) is 23 over 62 journals, in Geochemistry and Geophysics (rank 21 over 81) and in Meteorology and Atmospheric Sciences (rank 25 over 84). Figure 1 shows in which other journals SWSC articles are cited. The main journals that cite SWSC papers are the Astrophysical Journal, Astronomy and Astrophysics, the Journal of Geophysical Research, and the Geophysical Research Letters. But SWSC articles are now cited in all important journals relevant to geophysics and space research.

As an Open Access journal, each paper is widely accessible, not only to the entire research community, but also to any interested individual. According to EDP Sciences and to The Astrophysics Data System (ADS)/The National Aeronautics and Space Administration (NASA) database statistics, in 2016 a record of 3360 abstract downloads per month and of around 12,000 downloads for full texts (all formats, PDF, HTLM, and EPub) is reported.

The fact that this journal came about as a result of a community decision explains to a major extent these achievements. Another reason for the success of the journal is the level of excellence expected and achieved from the beginning, in order to meet the SWSC quality standards (Belehaki \& Lilensten 2013). Every submitted manuscript is first read by three to four members of the Editorial Board - including the Advisor and the Editors-in-Chief and potentially the Topical Editor-in-Chief - who write a pre-screening assessment. About $20 \%$ of the articles are rejected at this stage, often accompanied by advice for improving for a future submission. When an Associate Editor accepts to handle the review process, he/she may also recommend rejecting it, providing a thorough review. As in most peer-reviewed journals, the external reviewers - always at least two, sometimes three may also recommend rejecting an article. With this three-stage process, the rejection rate is about $40 \%$. This is a slight decrease from the time when the journal was first publishing due to the increase in quality of the submissions.

The number of submissions to the regular issues continued to increase to about 50 in 2015. Each topical issue received typically 10 to 15 submissions. Figure 2 shows the number of published articles since 2011. Next year, we expect three topical issues that will help increase the publishing frequency to about one paper per week.

Another important metric for the performance of SWSC is the handling time, which is the time from the day of submission till the day of online publication. The number of 


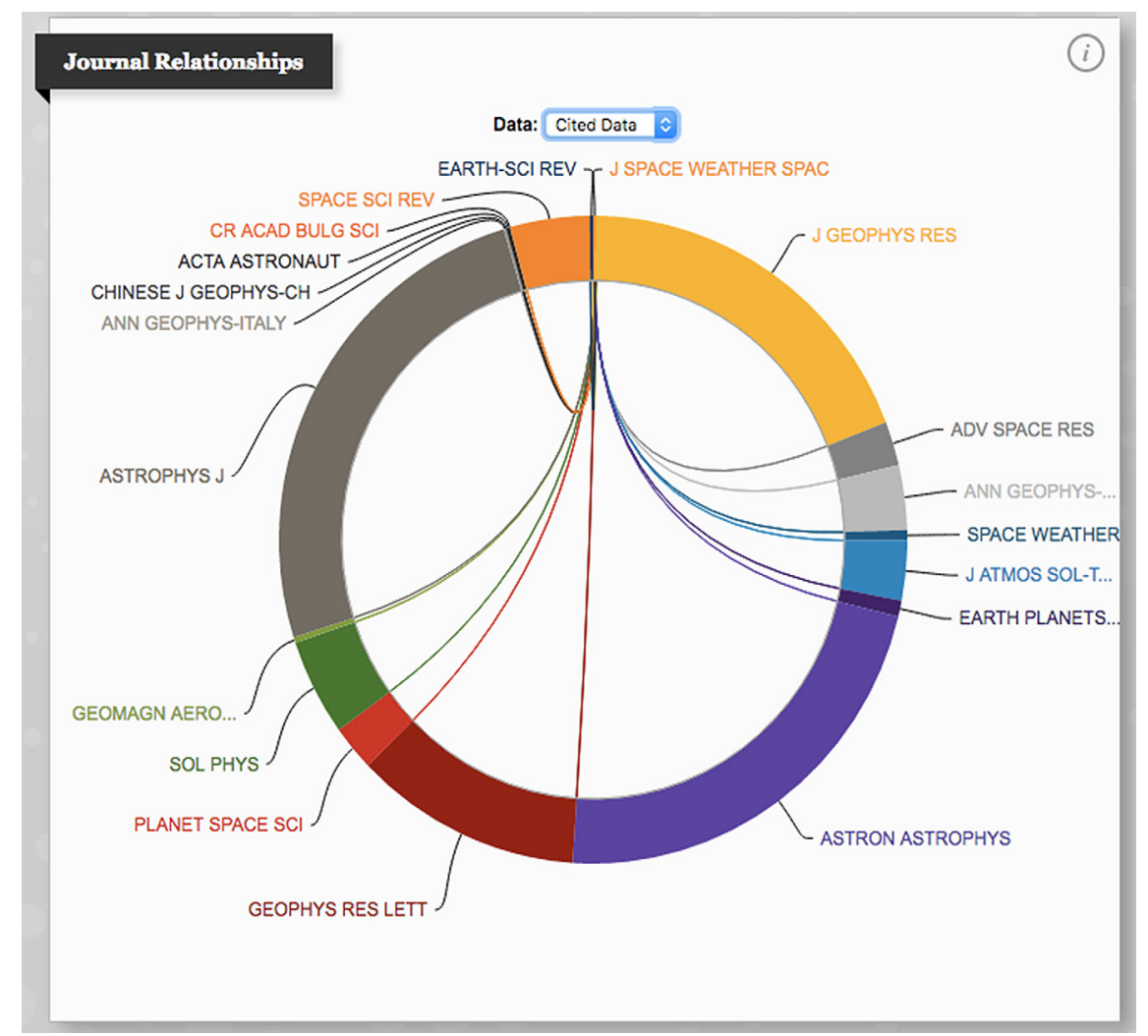

Fig. 1. Journals where SWSC articles are cited (Source "powered by InCites-Clarivate Analytics").

\section{SWSC publications per year}

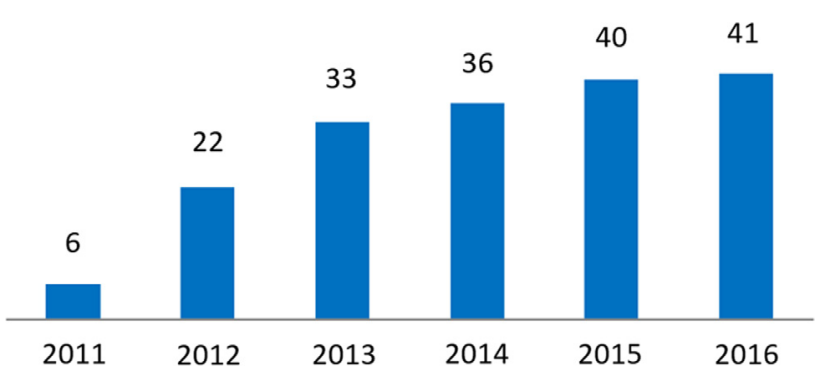

Fig. 2. Number of published articles in SWSC (up to 10 December 2016).

published manuscripts versus the handling time is presented in Figure 3 . The first quartile $(25 \%)$ is 153 days, the median is 216 days, and the third quartile (75\%) is 315 days. The chart comprises 176 published manuscripts in the regular and topical issues, up to 10 December 2016.

SWSC has now become one of the main publication media for the space weather and space climate community, with a number of papers already influencing research advances in the field.

\section{Pricing policy}

Producing a journal does involve some costs; below is a summary of the activities that have costs involved:

- Development and maintenance of a Manuscript Management System (system used by the editorial team to manage the workflow of papers).
- Language editing.

- Copy-editing of each paper to ensure consistency for all aspects of the manuscript (figures, references, etc.).

- Prepress work (layout) and publication of the online edition: with PDF, HTML, ePub formats, online material, figures and tables, etc.

- Archival and indexing services.

- Specialized services such as a dedicated website, marketing, etc.

The publication charges have increased to $800 €$ from December 1st, 2016. This price makes SWSC one of the least expensive journals in the category of international open access and peer-reviewed journals, in this discipline. ${ }^{1}$ This is due to the efforts EDPS makes in supporting our science, and this price will remain unchanged for the foreseeable future. This cost also now includes a new service: once an article is accepted, it will benefit from a language editing check by a professional language editor. This will help colleagues to publish excellent work that is professionally checked for the English language, grammar, and spelling.

\section{Topical issues}

SWSC publishes Topical Issues that emerge from the wider space weather and space climate community. A group of colleagues decides about the necessity to publish up-to-date research in a specific domain. The proposers provide to the Editors- in-Chief the aim and scope of the proposed

\footnotetext{
${ }^{1}$ In most of the journals publishing space weather related articles, the open access option costs $1500 \$$ to $3500 \$$.
} 


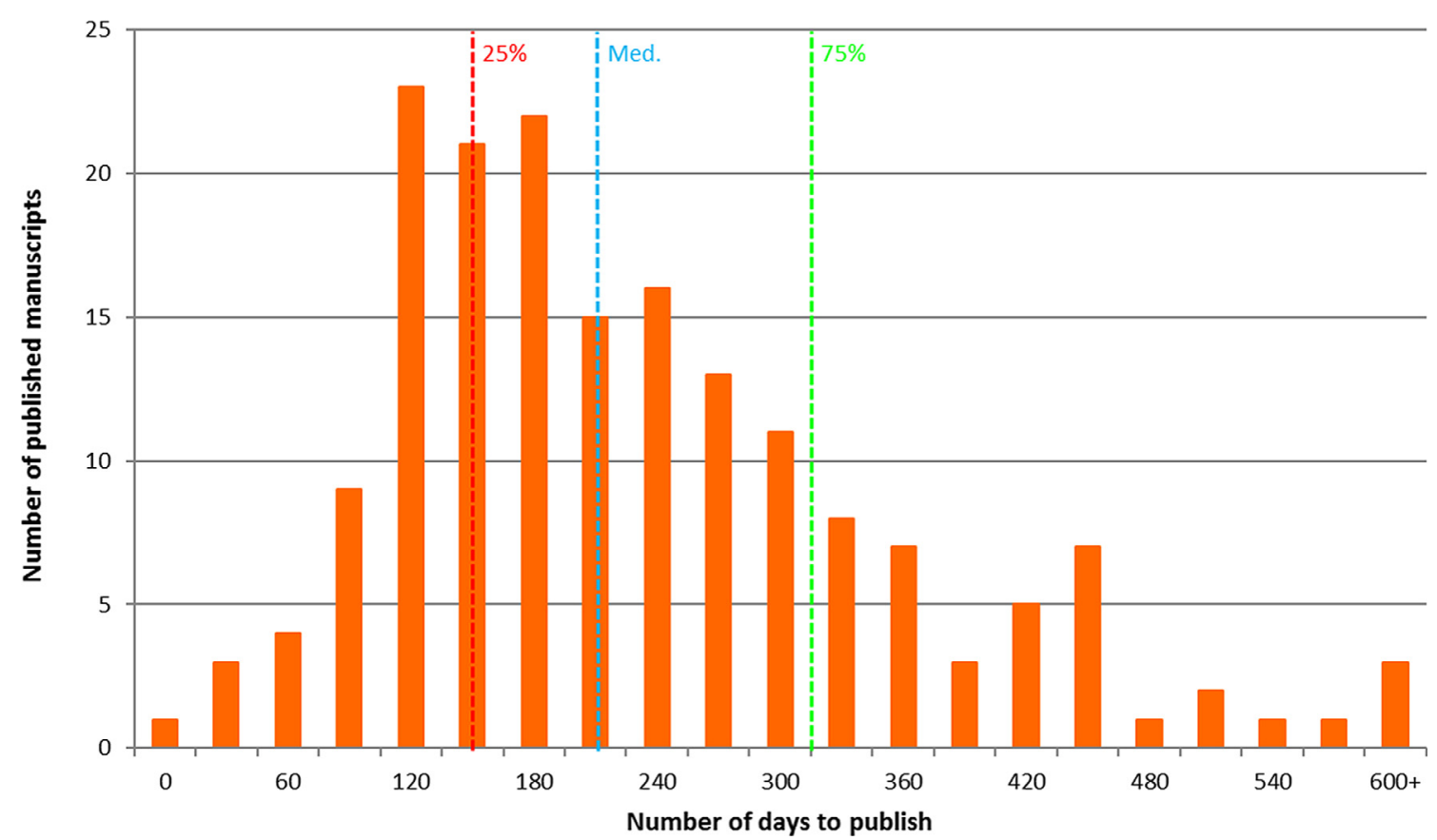

Fig. 3. The number of published manuscripts plotted versus the number of days required from submission to online publication (handling time). The figure presents the status on 10 December 2016.

Topical Issue, a list of topical Associate Editors and of potential submissions. The Editors-in-Chief take a decision on the proposal based on the scientific merit, the current scientific trends in the topic and on the organization potential of the proposers. Members of the regular Editorial Board also suggest Topical Issues from sessions they have attended at various meetings. SWSC has already published the following Topical Issues:

- Brightness Variations of the Sun and Sun-like Stars and Resulting Influences on their Environments (http:// www.swsc-journal.org/component/toc/?task=topic\&id=612).

- Scientific Challenges in Thermosphere-Ionosphere Forecasting (http://www.swsc-journal.org/component/toc/?task= topic\&id=551)

- Statistical Challenges in Solar Information Processing (http://www.swsc-journal.org/component/toc/?task= topic\&id=465).

- Satellite mission concepts developed at the Alpbach 2013 Summer School on space weather (http://www.swsc-journal. org/component/toc/?task=topic\&id=388).

- Solar variability, solar forcing, and coupling mechanisms in the terrestrial atmosphere (http://www.swsc-journal. org/component/toc/?task=topic\&id=250).

- Space Weather and Challenges for Modern Society (http:// www.swsc-journal.org/component/toc/?task=topic\&id=182).

- COST Action ES0803 (http://www.swsc-journal.org/ component $/$ toc $/$ ?task=topic\&id=145).

- EU-FP7 funded space weather projects (http://www.swscjournal.org/component/toc/?task=topic\&id=131).

- Space Climate (http://www.swsc-journal.org/component/ toc/?task=topic\&id=111).

All are online on the journal's website. The diversity of these issues shows that the journal is not limited to the science of space weather and space climate, but it is also open to applications. For each of these issues, The enthusiasm of the Topical Editor Board is the key to success.

\section{Outlook}

In the future, we will be focusing on maintaining and even improving the quality of the publication. A major driver for this is the enthusiasm of our editors. Their job is not trivial, it is time demanding and challenging because they have to invite the most competent referees, to critically evaluate their reports and sometimes to convey their own view to the authors - in addition to the referee reports - helping them to improve their manuscript. In order to work efficiently with the editorial team, our publisher renews the appointment of the editors every two years. This policy allows our editors to consider if they can still devote the time to be on the board, rather than commit them for an undefined time period. In addition, the renewal of the Editorial Board brings new ideas that constantly improve the editorial procedure. We always look for new Editors and this is an open invitation to the community.

One of the ideas which is under discussion in the Editorial Board is the introduction of a simple but clear data policy for the following reasons (whereby "data" includes observations and model or simulation results):

- Owners of the raw data must always be acknowledged and if they have specific Terms of Reference, these must be respected by the authors. Therefore, the source of the raw data must be revealed.

- The authors have to say if the raw data is publicly accessible. This is important for our readers in case they need touse the same data to reproduce the results of the paper. In the case that restricted data has been used, this must be highlighted. 
In the future, it may become necessary that the community adopts a data citation standard, such as the digital object identifier (DOI). That would allow the data generator and the data providers to be credited for their work to generate and make the scientific datasets available. In addition, it would allow any interested party to regenerate the results published in the paper. This is not an easy task and requires agreement on the standardization of data citation and the setup of an infrastructure to guarantee accessibility. There are a number of challenges that the community has to face as also discussed by Hapgood \& Knipp (2016) and a coordinated effort within our international community and with the scientific publishers is required to balance between the ideals of that data policy and its practical implementation. Data citation capabilities have advanced in recent years through investments in data infrastructure initiatives (FORCE11 2014; Belehaki et al. 2016). However, it is obvious that we are just in the beginning and it will take time and funding, but it is a necessary step toward the preservation and uninterrupted access to scientific data and the real open assessment of published results in scientific journals.

\section{References}

Belehaki, A., M. Messerotti, and M. Candidi. Developing Space Weather products and services in Europe - Preface to the Special issue on COST Action ES0803. J. Space Weather Space Clim., 4, E1, 2014, DOI: $10.1051 / \mathrm{swsc} / 2014032$.

Belehaki, A., and J. Lilensten. Editorial policies at SWSC. J. Space Weather Space Clim., 3, A13, 2013, DOI: $10.1051 / \mathrm{swsc} / 2013035$.

Belehaki, A., S. James, M. Hapgood, S. Ventouras, I. Galkin, et al. The ESPAS e-infrastructure: access to data from near-Earth space. Adv. Space Res., 58, 1177-1200, 2016, DOI: $10.1016 /$ j.asr.2016.06.014.

FORCE11. Data citation synthesis group: joint declaration of data citation principles. In: M. Martone, Editor. FORCE11, San Diego, CA, 2014, [Available at https://www.force11.org/group/ joint-declaration-data-citation-principles-final].

Hapgood, M., and D.J. Knipp. Data citation and availability: striking a balance between the ideal and the practical. Space Weather, 14, 919-920, 2016, DOI: 10.1002/2016SW001553.

Lilensten, J., and A. Belehaki. Editorship at SWSC. J. Space Weather Space Clim., 1 (1), E01, 2011, DOI: $10.1051 /$ swsc/2011002.

Cite this article as: Lilensten J, Belehaki A, Watermann J, Janssens J \& Henri A. The Journal of Space Weather and Space Climate - the first six years: status and evaluation of published papers and policies. J. Space Weather Space Clim., 7, E1, 2017, DOI: 10.1051/swsc/2017002. 